\title{
Alexandre Eulalio, POeta, diante de Quirino Campofiorito, PINTOR
}

Francisco Roberto Papaterra Limongi Mariutti

Universidade de São Paulo

Resumo

$\mathrm{O}$ artigo está centrado na análise de um poema escrito por Alexandre Eulalio, conhecido ensaísta. Essa análise baseia-se na concepção de Goethe de poesia de ocasião - palavra que significa, no contexto específico, uma exposição de telas do pintor Quirino Campofiorito.

Abstract

The article is focused on analisys of a poem written by Alexandre Eulalio, know essayist. This analysis is based on Goethe's conception of poetry of occasion - word that means, in the specific context, an exhibition of the painter's screens Quirino Campofiorito.
Palavras-chave

Alexandre

Eulalio; poesia de ocasião;

Goethe;

Quirino

Campofiorito.

Keywords
Alexandre
Eulalio; poetry
of occasion;
Goethe;
Quirino
Campofiorito. 
ma das características da obra de Alexandre Eulalio (adiante AE) é a de promover o concurso de vários saberes e expressões artísticas em suas análises de um objeto - obra, escritor, pintor, fenômeno humano. Depois de visitar a exposição de óleos de Quirino Campofiorito, na Galeria Acervo, em dezembro de 1984, no Rio, a opção foi escrever um poema, e não um ensaio, como seria a norma, da qual AE era mestre em desviar-se. Está na melhor companhia: Baudelaire, Valéry, Octavio Paz, Murilo Mendes, Jorge de Lima e João Cabral também responderam em forma de poesia ao estímulo recebido de artistas plásticos.

Trata-se de poema de quem - experimentado visitante de museus mundo afora e leitor agudo de Panofsky e Francastel - conhece pintura como ninguém, o que pode ser constatado através da leitura do ensaio "De um capítulo do Esaú e Jacó ao painel dO último baile", ${ }_{1}^{1}$ em que AE faz iluminarem-se mutuamente um trecho do romance de Machado de Assis e um óleo de Aurelio de Figueiredo ambos tematizam o famoso baile da Ilha Fiscal -, o que apenas um estudioso de história dotado de imaginação e finura, um conhecedor da obra do romancista e um perito em artes plásticas poderiam fazer; AE era os três ao mesmo tempo.

$$
\begin{gathered}
\text { A Quirino Campofiorito }{ }^{2} \\
\text { olhando suas noventa telas expostas } \\
\text { em dezembro de } 1984 \text { numa } \\
\text { galeria do Rio de Janeiro }
\end{gathered}
$$

O Autor pigarreia

buscando um tom joão-cabral à altura da circunstância:

${ }^{1}$ Ensaio de Alexandre Eulalio publicado em Tempo reencontrado, org. Carlos Augusto Calil, São Paulo, Editora 34 e Instituto Moreira Salles, 2012.

${ }^{2}$ Poema publicado em Alexandre Eulalio diletante, Campinas, DTL-IEL-Unicamp, 1993. 
Mas não consegue manter a nota alheia e prossegue de qualquer jeito, manquitolando:

Divaga:

Procura fazer

um balanço

das telas:

\author{
Igual a si mesmo \\ o todo articulado \\ articulando o vivo \\ alinhado sobre a mesa: \\ um alfabeto de formas \\ em estado de natureza.
}

Sossego.

Range a cor

entregue ao seu peso.

O olho escuta

nítido

a forma pura

eriçada na voluptuosa voluta

helicoidal.

Mar recomeçado

sobre a mesa posta

- areia profunda.

Jean-Jacques passeia pela praia.

Sossego.

No diálogo silente

os pintores e as colheitas deles

o dentro da casa

a caixa da casa

a casca da casa

a casca de osso

o caramujo

marujo náufrago.

Folhagem escura

copo de vinho

pão.

A carne da fruta

Três limões em campo elétrico.

Pedra mármore mêmore.

A silva de Estêvão:

galhos pesados.

Mangas. Mamão. Caju.

O trigo soterrado das raízes.

Sertão de Monte Santo.

A fratura exposta das colunas.

A trompa do búzio

sem sopro. 
Algumas insistências:

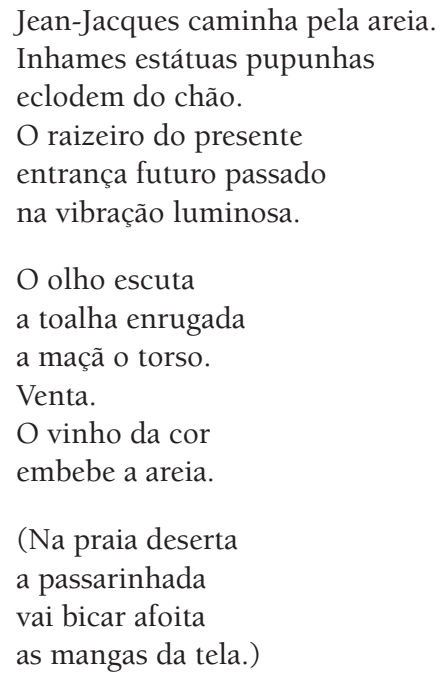

Alexandre Eulalio Janeiro, 1985

Esse poema seria outra coisa se fosse limitado aos versos centrais; os apontamentos, postos entre estrofes, à esquerda, introduzem um ser, o Autor, ou ainda, a função exercida por ele - aqui em negrito, para distinguir do ser civil que assina e data a obra -, que conjuga todos os verbos, sempre enunciativos, em tom prosaico. Autor tem a entrada impedida nos versos centrais, onde não cabem esse tom nem a primeira pessoa. Há um cordão de isolamento entre apontamentos e versos, em vários níveis, a começar pelo plano gráfico, da mancha da página. No âmbito sintático, Autor é sujeito de todos os verbos das rubricas, ao passo que nos versos, quando há verbos, estes referem fenômenos naturais ou artísticos, cobrindo o arco que irrompe no artista e finda no observador; um certo Jean-Jacques [Rousseau?], sujeito de uma ou outra oração, não ocupa lugar distinto de inhames ou caramujos.

As rubricas podem ser consideradas comentários marginais de leitor, indicações de andamento da partitura musical, orientações do roteirista para o diretor de cinema. Autor centra-se em si mesmo, autorreferente, ao mesmo tempo que irônico e autoirônico em cada vírgula, questionador de si, o que é o exato oposto da postura objetivante, apolínea, analítica mesmo, perceptível nos versos. Nestes, o pronome de primeira pessoa não conjuga nenhum verbo, o que não quer dizer ausência de expressão lírica ou distância entre observador e objeto - o conjunto de telas de Campofiorito. Resumindo: de um lado, Autor em desassossego; de outro, eu tão na cara, tão tomado de admiração por aqueles óleos, que nem precisa aparecer.

O pigarro - autoironia pura - dos apontamentos sinistros é linguagem reduzida à função fática, apenas expressão necessária para invocar João Cabral, citado aqui como poeta que desentranhava a crítica de arte do interior de uma poética muito particular. De fato, o tom cabralino, anunciado na esquerda, aparece ao 
centro; a agudez vigorosa da linguagem, tensa feito corda de puxar barco em mar revolto, está presente, de forma bem diversa, em ambos os poetas, em trechos de poemas-homenagens a Sevilha e a Roma-Murilo Mendes:

"Cantei mal teu ser e teu canto enquanto te estive, dez anos; cantaste em mim e ainda tanto, cantes em mim teus dois mil anos. Cantas em mim agora quando ausente, de vez, de teus quantos, tenho comigo um ser estando que é toda Sevilha caminhando."

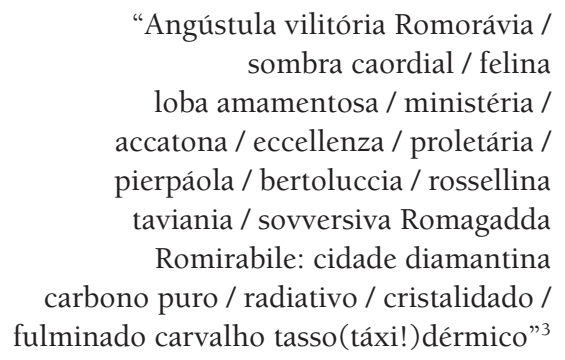

Digamos que de um lado se tem um arquiteto-urbanista que elabora um discurso sobre o canto intrínseco da cidade; de outro, um cineasta à maneira de Godard perscrutando ruas romanas, referências políticas e artísticas - em ambos são perceptíveis vigor, rigor, alta criatividade, alta poesia.

Própria de quem não se leva muito a sério - o que, paradoxalmente, não é antônimo de ser sério -, a autoironia, de que AE abusava, está presente nos apontamentos logo de cara: não conseguir manter a nota alheia, prosseguir de qualquer jeito, manquitolar, divagar, procurar fazer um balanço e insistir são termos que dão sequência, sempre em tom rebaixado, a pigarrear; a obra de Campofiorito está lá no alto, Autor fica cá embaixo. Ou ainda, nas rubricas prosaicas e marginais à esquerda, e de lá não sai. A tensão é perceptível: o movimento de aproximação da poesia rumo à pintura - topos da invenção de AE, que é apontamentos + versos sofre desvios oriundos da postura do Autor, que, seguindo a tradição brasileira do poeta menor - expressão muito afim ao sentido em que Erich Auerbach utilizou a expressão sermo humilis em estudos clássicos, ${ }^{4}$ mas não idêntica -, o sujeito do discurso define-se como incapaz de dar conta de seu objeto, mas não emudece

3 "Presença de Sevilha", in João Cabral de Melo Neto, Poesia completa e prosa, Rio de Janeiro, Aguilar, 1994. "LT a Murilo Mendes", in Alexandre Eulalio diletante, Campinas, DTL-IEL-Unicamp, 1993.

${ }^{4}$ Duas obras de Erich Auerbach dizem respeito ao tema: Lingua letteraria e pubblico nella tarda Antichità latina e nel Medioevo, trad. F. Codino, Milano, Feltrinelli, 2007; Dante: poeta del mundo terrenal, trad. Jorge Seca, Barcelona, Acantilado, 2003. Os poetas brasileiros autointitulados menores, a que se faz referência aqui, são Manuel Bandeira, Vinícius de Morais, Mário Quintana. 
diante da grandeza deste e elabora um texto que faz a figuração do externo lado a lado à exposição do sentimento íntimo de rebaixamento: isso pode ser lido - ou mesmo visto - nas duas rubricas iniciais. Há nos versos um tom lírico - que nunca é exposto através de um eu gramatical - que refaz o diálogo entre sujeito poético e pintura. É como se houvesse um lirismo impessoal, se for possível falar assim, que impregna o poema; Autor é antes quem sopra o espírito lírico, mas não diz quem o faz; opta pelo lado escuro e esquerdo, pela sombra, pela invisibilidade. A relação entre Autor e esse espírito é central na leitura de "A Quirino Campofiorito" que está sendo proposta, daí tantas linhas a respeito do assunto. Uma bifurcação no jogo dos signos é visível já a partir deste ponto: de um lado, continuidade entre o ser e sua criação; de outro, barreira e descontinuidade - literalmente visível, pela posição no papel - entre criador e criatura.

A base material da linguagem é muito explorada neste poema, apontando para uma densa expressividade. Como exemplo, a presença de assonâncias - /ar/ e /al/ - na primeira estrofe, em pares formados a partir de um eixo horizontal de simetria, demarca um conjunto de versos carregados de, entre parênteses, explícitos artificialismos da linguagem, que seguem na mão contrária ao sentido construído pela sequência dos versos, que aponta para uma linguagem supostamente natural, livre de artifícios - um alfabeto de formas / em estado de natureza.

1. neutro, quanto à assonância

2. assonância na terceira sílaba

3. assonância na primeira sílaba (eixo de simetria)

4. assonância na primeira sílaba

5. assonância na segunda sílaba

6. neutro, quanto à assonância

Ser uma coisa, parecer outra; ser artifício, parecer forma natural: não fosse literatura, seria engodo ideológico. É da essência da linguagem, enquanto instrumento de representação, essa contradição incontornável; é da essência da poesia esse jogo de procura e esconde-esconde entre a materialidade dos signos e seus significados. Moral da história: a representação da natureza é antes conquista formal construída por mil artifícios, o que tem muito a ver com as telas de Campofiorito em pauta. Nessas, a harmonia - forma artística da totalidade - entre natureza e cultura é ideal a ser perseguido; atingido ou não, são outros quinhentos. AE responde a essa busca construindo imagens em que certa natureza e certa cultura se cruzam: voluptuosa voluta helicoidal é descrição de conchas cuja arquitetura corresponde a formas geométricas perfeitas; é também uma sequência de palavras em que a primeira se projeta na segunda e a terceira não tem nada a ver com as anteriores. Harmonia totalizante num sentido; desarmonia noutro. Nenhuma linha reta; encontros são posteriores e talvez resultado de uma série de desencontros.

Há um jogo sintático ousado na primeira estrofe: os modos verbais são particípio e gerúndio, a que a gramática atribui um lugar secundário - orações redu- 
zidas subordinadas, nunca principais - na organização do período; no lugar do indicativo - o modo das orações completas, principais, desenvolvidas -, formas gramaticais menores: fragmentárias, incompletas e outras coisas de não, ${ }^{5}$ ou de menos; uma espécie de sutil revolução faz, em suma, o secundário ocupar o lugar do principal. Com muitos ecos: o menor no lugar do maior; o pobre, ao invés do rico; o simples que resulta de uma operação estética muito elaborada - estilização -, e não o rebuscado. Entra nesse jogo o modo de Quirino Campofiorito compor suas pinturas: as telas em pauta são ao mesmo tempo marinhas e naturezas-mortas; ${ }^{6}$ das primeiras subtrai a perspectiva aberta - do alto ou do rés do chão, como as de Pancetti -; das segundas, retira o cenário frio, morto e distante, e o substitui pelos sempre vivos praia e mar, o que provoca uma dinâmica quase narrativa nas obras, ainda mais se nessas constar figurações humanas. Frutas inteiras ou cortadas, acompanhadas de concha ou outro ser marinho, em close; pouco mais que linhas de azul do mar ao fundo e nuances de cores nuançadas bege, cinza - formam a areia das praias, nas quais uma vez ou outra uma mínima figura humana tem vez. Noutras palavras, vivificando a natureza-morta e dando toques orgânicos à mineralidade das marinhas, Campofiorito decompõe formas fixas de pintura e recompõe a organização das manchas de cor - o que nos versos foi chamado de alfabeto de formas em estado de natureza; noutras palavras, a sintaxe das pinturas em pauta também é subvertida por uma resoluta atitude do pintor. Assim, faz sentido considerar que a linguagem inventada dos versos responda à linguagem do artista plástico, de certa maneira aquela impregnando-se dessa. É como se o poema fosse escrito - abstraído o jogo de palavras - sob o impacto causado pela experiência estética provocada pela obra de Quirino Campofiorito, e não sobre o artista e sua obra, como seria mais adequado dizer se estivéssemos diante de um ensaio. Nesse sentido, cabe incluí-lo na categoria poesia de ocasião, definida por Goethe ${ }^{7}$ a que se retornará.

O tom joão-cabral está presente também nesta estrofe:

\author{
No diálogo silente \\ os pintores e as colheitas deles \\ o dentro da casa \\ a caixa da casa \\ a casca da casa \\ a casca de osso \\ o caramujo \\ marujo náufrago.
}

\footnotetext{
${ }^{5}$ Expressão de um personagem dotado de espírito crítico em "Morte e vida Severina", in João Cabral de Melo Neto, Poesia completa e prosa, op. cit.

${ }^{6}$ Para que não haja mal entendidos: marinha e natureza-morta aqui estão referidas como formas de pinturas que seguem convenções predefinidas.

${ }^{7}$ Johann Wolfgang Goethe, Memórias: poesia e verdade, trad. Leonel Vallandro, São Paulo, Hucitec, Brasília, Unb, 1986.
} 
A sequência das aliterações - casa / caixa / casa / casca / casa / casca - é rompida pela delicadeza sibilante de osso, da mesma forma que no último verso a rima interna em ujo não se projeta na última palavra, marcada pela surpresa esdrúxula; um princípio de organização sonora pode ser daí depreendido: a expectativa cômoda das formas fixas e das organizações banais de linguagem não são atendidas nesse poema, que, pelo contrário, propõe jogos que rompam os automatismos. No plano sintático, algo da mesma ordem: os verbos, em torno dos quais a linguagem prosaica constrói sua ossatura, são abolidos, em nome de uma concretude mais substantiva e vibrante dos versos. Ambos procedimentos aqui apontados são citações-homenagens ao modo como o autor de Educação pela pedra compõe poemas.

O poema contém uma série de imagens que fazem referências mais ou menos cifradas à História e à História da Arte, como Pedra mármore mêmore: o último termo, adjetivo raríssimo, indica a qualidade daquilo que porta memória, portanto História; Campofiorito compôs muitas telas em que fazia a representação de partes de esculturas oriundas da Grécia e Roma Antigas ou da França neoclássica uma metalinguagem, noutras palavras - em meio a elementos naturais, tudo disposto em forma de assunto de vivas naturezas-mortas. Uma dessas, se não estiver enganado, contém um busto de Rousseau, daí dois versos: Jean-Jacques passeia pela praia e Jean-Jacques caminha pela areia. Ainda: Campofiorito foi estudioso da História da Arte Brasileira e atribuía grande relevo à Missão Artística Francesa contemporânea do primeiro romantismo e difusora, nos trópicos, do mito do bom selvagem. ${ }^{8}$ O trigo soterrado das raízes. Sertão de Monte Santo. A fratura exposta das colunas. A trompa do búzio sem sopro. Os versos que contêm explícitas referências históricas e literárias - a cidade baiana devastada, central no episódio de Canudos, revisitada pela Coluna Prestes; a expressão fratura exposta, pela qual Oswald de Andrade era obcecado, ${ }^{9}$ e a marca do tempo, numa visão de sabor clássico, que torna ruína o antigo esplendor -, são "cercados" por dois outros versos que fazem figurações da natureza mutilada e, a partir dessa transformação negativa, projetam a mutilação no universo da cultura. A primeira imagem aponta para o alimento trigo, pão - que não alimenta, pois, soterrado, não está ao alcance da mão; trompa e búzio, que têm significados específicos no mundo natural e no mundo da cultura, aparecem aqui sem uso, sem expressão - sem sopro (humano, portanto sem música?; do Espírito, portanto morto?; ambos?). É a parte do poema mais intrigante, mais difícil de penetrar; recorra-se a outro poeta-crítico para melhor se aproximar:

\footnotetext{
em surdina

ligeira passa a felicidade pelas minhas pernas trêmulas e o súbito, embargado soluçante desejo de viver
}

\footnotetext{
${ }^{8}$ Quirino Campofiorito, A Missão Artística Francesa e seus discípulos: 1816-1840, Rio de Janeiro, Edições Pinakotheke, 1983.

${ }^{9}$ Em alguns parágrafos da "Digressão sentimental sobre Oswald de Andrade" Antonio Candido trata dessa obsessão do autor de Serafim Ponte Grande; in Vários escritos, São Paulo, Duas Cidades, 1977. AE foi um leitor agudo e constante de Oswald.
} 


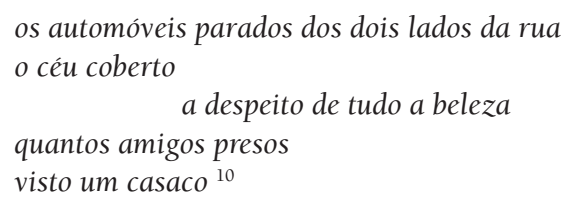

O topos da celebração do Belo é central nas obras em pauta - tanto a pintura de Campofiorito quanto o poema de $\mathrm{AE}$-, mas isso não significa que rejeitem o negativo, a ruína, o que não se exprime ou o que não possa se exprimir, o mutilado, o clamor dos vencidos. É como se esse lado obscurecido se unisse ao Belo e ambos reclamassem sua parte na dialética da História.

O raizeiro do presente entrança futuro passado na vibração luminosa - o objeto natural e a arte atravessados pelo tempo, portanto pela História, horizonte necessário, em que a totalidade concebida pelo poema se projeta; instância na qual, enfim, se deve projetar a leitura desse poema. A silva de Estêvão: galhos pesados trata-se de menção a Estêvão Silva, pintor formado pela Academia Imperial de Belas Artes, portador de exímia acuidade técnica voltada para naturezas-mortas, sobretudo de frutas tropicais, abertas ou inteiras; está presente também um jogo de palavras que aponta para selva - do latim silva -, ambiente natural apreendido, objeto da pintura de Estêvão e de Campofiorito, e a concepção informada pelo Caldas Aulete, de junção de partes literárias ou científicas sem qualquer ordem ou método, que certamente AE conhecia e nela se reconhecia como praticante do "método" nesse próprio poema. Assim, nesse mesmo trecho, o peso dos galhos pode ser entendido como referência ao peso da História sobre as costas de artista que pratica as mesmas formas - naturezas-mortas - de outro, que as teria elevado a nível absoluto. A última estrofe é uma resposta a essa questão: a perfeição técnica de Campofiorito é de tal ordem que provoca a confusão de passarinhos, que não distinguem o natural real do natural apreendido pelo artista.

A motivação desse poema é o comentário protocolar, em livro próprio, de amigo de artista que é convidado para vernissage; AE optou por comentar de forma não habitual - através de poema enviado ao pintor algum tempo depois (as datas dezembro de 1984 e janeiro de 1985 - podem ser lidas no corpo do texto) -, escrito a mão. A disposição gráfica da invenção de $\mathrm{AE}$ - coluna da esquerda restrita a rubricas, coluna do centro de versos agrupados em estrofes, canto direito inferior destinado à assinatura e data - reproduz, ao menos em parte, um quadro; a parte sinistra seria algo como um esboço, não totalmente levado adiante; a coluna central acolhe dados, referências e procedimentos da obra de Campofiorito, sem hierarquizá-los nem colocá-los em perspectiva, como se formassem um retábulo de feição medieval; assinatura e data onde normalmente artistas plásticos assinam e datam. Goethe definiu a poesia de ocasião como sendo a continuidade no mundo da linguagem de uma experiência vital; aqui, vitalidade e estética se identificam e, ao combinarem-se desse modo específico, apontam para uma totalidade - ou uma

10 "Convalescença”, in Roberto Schwarz, Corações veteranos, Rio de Janeiro, Frenesi, 1974. 
certa totalidade, vá lá. Assim, leia-se como, nas esquinas do poema, cruzam-se qualidades do mundo sensível com as sensibilidades humanas, organizando vários segmentos: em range a cor, estão presentes peso e luz como qualidades da matéria, percebidas pelo tato e pela visão. Em mar recomeçado sobre a mesa posta a aliteração em $/ \mathrm{ma} / \mathrm{e} / \mathrm{me} /$ aproxima termos opostos (enorme, pequeno; barulhento, silencioso; vivo, morto); para a percepção plena da imagem surreal e da conjunção surpreendente é requisitada a imaginação visionária, assim como a audição desarmada para ouvir a aliteração, o barulho, o silêncio. Na mesma linha, diálogo silente necessita de audição e contra-audição ao mesmo tempo para ser captado. Três limões em campo elétrico é imagem que contém acidez, alimento, cor, frisson, energia: a mobilização de vários sentidos é indispensável para apreendê-la. Textura, luz, som, senso estético são qualidades presentes em o olho escuta nítido a forma pura e o olho escuta a toalha enrugada a maçã o torso, que imaginação criadora e crítica, tato, visão e audição mobilizam-se para apreender. Que não se veja aí algo da ordem da compensação de uma incapacidade de visão - apenas um exemplo - por uma maior sensibilidade auditiva, mas um processo que torna mais finos e agudos todos os sentidos, desencadeado por aquela combinação de experiências vitais e estéticas adrede referida. A busca de totalidade é também busca da identidade entre sujeito da enunciação e objeto enunciado. O termo sentidos, ainda que diga respeito antes de mais nada aos cinco modos básicos de percepção do mundo, inclui os sentidos do Espírito que projetam materializar-se, como vontade, curiosidade, desejo, amor, ser correspondido. Está em pauta um valor: a continuidade entre a vida efetivamente humana e a vida do Espírito, enquanto busca idealizada do Belo - indissociada da busca totalizante do Bom, do Justo e do Verdadeiro na concepção platônica - passível de tornar-se História. ${ }^{11}$

Alex, lembra que você sempre mencionava Mallarmé e as implicações éticas, além das estéticas, de donner un sens plus pur aux mots de la tribu? Um desafio e tanto, que você, sempre disposto a pegar touro à unha, encarou muitíssimo bem, maravilhosamente. Pois é, o projeto do velho Stéphane não era sopa...

\footnotetext{
${ }^{11}$ Para estas últimas linhas, apoio-me numa leitura livre de "Propriedade privada e comunismo", em que consta a famosa frase a formação dos cinco sentidos é um trabalho de toda história do mundo até aqui. Letras maiúsculas para certos substantivos no interior da frase são tributo à Filosofia Clássica Alemã. Karl Marx, Manifestos econômicos-filosóficos (Trad. Jesus Ranieri). São Paulo, Boitempo, 2004.
} 